\title{
Re: Atrioventricular septal defect with common atrioventricular junction, common arterial trunk and severe coartation of the aorta in a patient with Down's syndrome
}

Sir,

We read the interesting paper by Singh and Pettersen $^{1}$ reporting on a patient with Down's syndrome with atrioventricular septal defect and common atrioventricular junction, common arterial trunk and aortic coartation. The association between atrioventricular septal defect with common arterial trunk and usual atrial arrangement is very rare. ${ }^{2}$ Because of this, therefore, we report here on two interesting cases recently observed by our own group.

The first patient was a nonsyndromic neonate with atrioventricular septal defect with common atrioventricular valve and common arterial trunk with a confluent pulmonary arterial segment, the so-called "type 1". Interestingly, this patient was the first cousin of a nonsyndromic child with interruption of the aortic arch between the left common carotid and subclavian arteries, the "type B" variant. ${ }^{3}$ The second patient had Down's syndrome with common arterial trunk and interrupted aortic arch, who presented also a "cleft" of the otherwise normal mitral valve. ${ }^{4}$

A common arterial trunk is extremely rare in patients with Down's syndrome, but in both our second case $^{3}$ and in the case reported by Singh and Pettersen, ${ }^{1}$ this malformation was associated with obstruction in the aortic arch, in spite of the fact that isolated aortic coarctation or interruption is very rare in the setting of trisomy 21 . All these observations confirm the mysterious interrelations that still exist between genetics, familial recurrence and complex congenital cardiac defects.

$$
\begin{array}{r}
\text { Claudia Saffirio, Anna Chiara Vittucci } \\
\text { Bruno Marino } \\
\text { Pediatric Cardiology } \\
\text { Department of Pediatrics } \\
\text { University of Rome } \\
\text { Italy }
\end{array}
$$

\section{References}

1. Singh HR, Pettersen MD. Atrioventricular septal defect with common atrioventricular junction, common arterial trunk and severe coarctation of the aorta in a patient with Down's syndrome. Cardiol Young 2007; 17: 226-228.

2. Marino B, Ballerini L. Atrioventricular septal defect associated with anomalies of the aortico-pulmonary septation. In: Quero Jimenez M, Martinez RA (eds). Pediatric Cardiology. Editiones Norma, Madrid, 1988, pp. 172-178.

3. Digilio MC, Marino B, Musolino AM, Giannotti A, Dallapiccola B. Familial recurrence of nonsyndromic interrupted aortic arch and truncus arteriosus with atrioventricular canal. Teratology 2000; 61: 329-331.

4. Francalanci P, Gallo P, Dallapiccola B, Calabrese G, Marino B. A genetic assessment of trisomy 21 in a patient with persistent truncus arteriosus who died 38 years ago. Am J Cardiol 1997; 79: $245-247$. 